\title{
EVALUATION ON FAILURE OF AN AUTOMOBILE DRIVE SHAFT
}

\author{
G. Srikanth Reddy ${ }^{1}$
}

\begin{abstract}
This paper deals with design and analysis of a drive shaft. During the transmission of power from the engine to the differential gear box of a rear wheel drive vehicle there is a problem of failure after long run of the vehicle due to low specific stiffness and strength of the material. The drive shaft should be capable to provide smooth and uninterrupted power transmission at varying speeds required by the vehicle.

A single piece drive shaft can be preferred in present market instead of a two piece drive shaft so that the weight of the drive shaft can be reduced. Presently used materials in the market for manufacturing are Cast Iron, Cast Steel. The purpose of this paper is to design the drive shaft made of Ni-Cr steel and compare it with steel material. The design is done in Solid works software and analyzed using ANSYS. The justification has been done by considering a full literature review.
\end{abstract}

Keywords - Modeling, Analysis, Steel and Nichrome Steel.

\section{INTRODUCTION}

The propeller shaft or a drive shaft is a unit of the automobile transmission system that connects the gear box output shaft to the input shaft of the differential at the rear axle. It transmits the power from the engine, clutch and gear box to the driving wheels of the vehicle through final drive and differential unit. It has to perform two functions. One is to transmit motion at an angle which is varying frequently and the other is to accommodate changes in length between the gear box and rear axle.

Due to its longer length and high speeds, the propeller shaft has a tendency to vibrate at certain critical speeds. The critical speed varies directly as the shaft diameter and inversely as the square of its length. To keep theoretical speed frequency above the driving speed range, the propeller shaft $\mathrm{s}$ need to be made with diameter as large as possible compared to its length. However, the increase in diameter increases its moment of inertia which would decrease its acceleration and deceleration. To minimize the whirl, achieve the decrease in shaft length by extending the rear end of transmission main shaft and housing or by extending the final drive pinion shaft housing or make use of two piece shaft. For small vehicles single length and for large vehicles centre of the shaft is supported by a bearing unit.

The torque that is produced from the engine and transmission must be transferred to the rear wheels to push the vehicle forward and reverse. The drive shaft must provide a smooth, uninterrupted flow of power to the axles. The drive shaft and differential are used to transfer this torque.

\section{LITERATURE REVIEW}

This paper presents the characteristic details of propeller shaft to substitute its material with composite material and suitability of material is analyzed by evaluating and comparing stress distribution \&amp; deformation within the

\footnotetext{
${ }^{1}$ Department of M echanical EngineeringAVN Institute of Engineering \& Technology, R.R Dist, Telangana, India
} 
shaft to replace the steel drive shaft with a piece of E-glass/ epoxy and E-carbon/epoxy with the help of material properties. The 3D modeling and assembly of Cardan shaft was done using CATIA V5 R21 software. Analysis is performed by using commercial FEA software ANSYS by considering static structural, Rigid dynamics and modal analysis to estimate deformation, stress under given loads and frequencies. The main objective of this paper is deduction of weight of an automobile transmission. Muni kishore, Jaligam Keerthi, Vinay kumar [1].

Virendra V. Maheta, Anup B. Patel. Study covers design, analysis and development of drive shaft for automobile applications. This covers dimension calculations of drive shaft based on engine power required. Accordingly shaft couplings e.g. universal joints, transmission gears for axle and axle design will be performed considering all static and dynamic loads acting upon it. All design process will be performed with aid of FE analysis using ANSYS software. When study has been carried out for different fiber angles for composite layers, it has been observed that $90^{\circ}$ angle of fibers is providing better fundamental frequency compared to other angles [2].

Deepti kushwaha, Gaurav Sa xena. Almost all automobile vehicles having transmission shafts. Present time the main issue of automobile industry are weight reduction. The weight reduction of the drive shaft can have a certain role in the general weight reduction of the vehicle and is a highly desirable goal. Substituting composite structures for conventional metallic structures have many advantages because of higher specific stiffness and strength of composite materials [3].

\section{III.OBJECTIVE}

To design the drive shaft made of Ni-Cr steel and compare it with steel material. The design is done in Solid works software and analyzed using ANSYS.

\section{DESIGN OF DRIVE SHAFT}

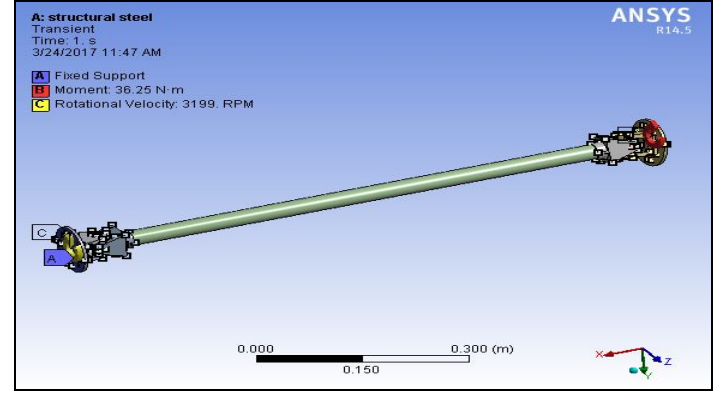

Fig.1. Steel

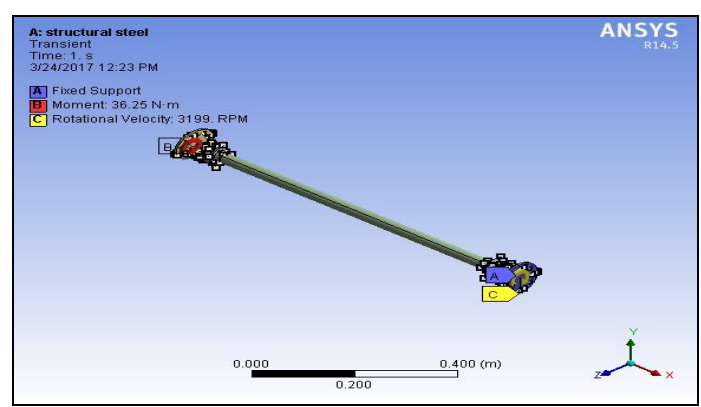

Fig.2. Nichrome

Fig.1. \& Fig.2. At A the shaft is fixed, at B the moment is $36.25 \mathrm{~N}-\mathrm{m}$; at $\mathrm{C}$ the rotational velocity is $3199 \mathrm{rpm}$.

\section{ANALYSIS}

\section{Meshing:}

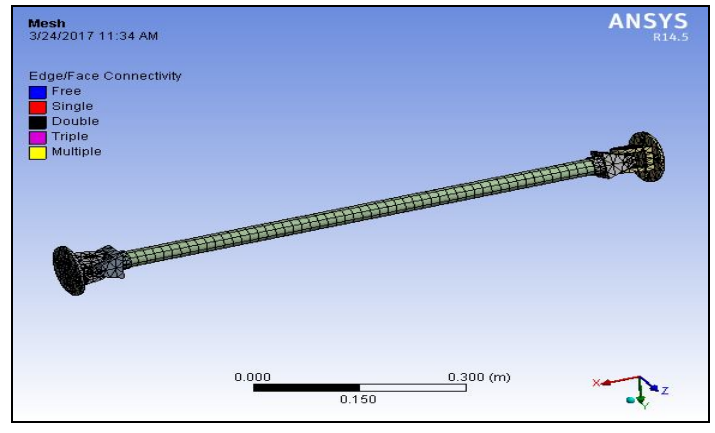

Fig.3. Steel

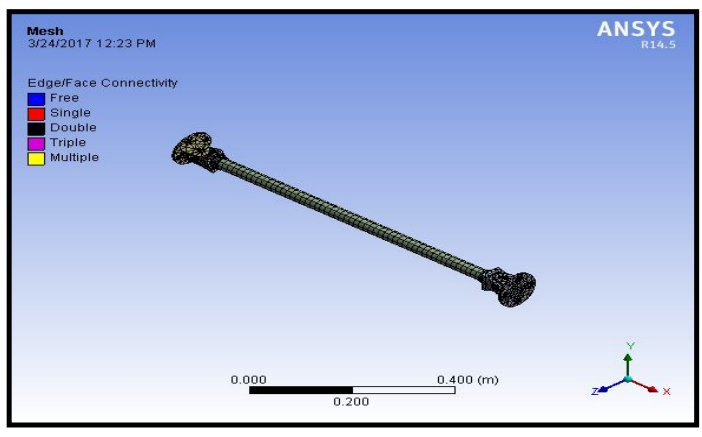

Fig.4. Nichrome

Stress: 




Fig.5. Steel

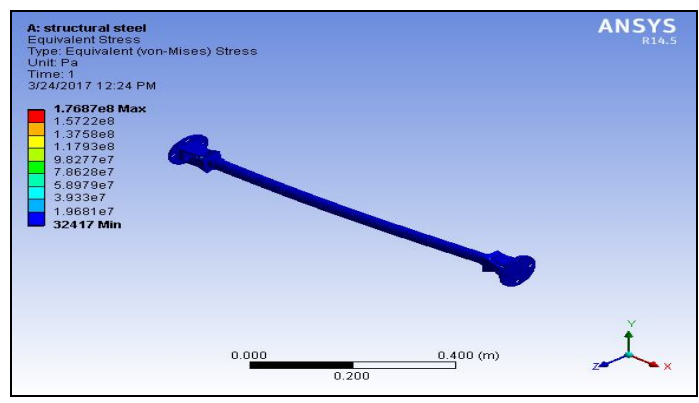

Fig.6. Nichrome

Fig.5.The maximum stress for Steel is $1.7187 \mathrm{e} 8$ and minimum stress is 31679

Fig.6.The maximum stress for Nichrome is $1.7687 \mathrm{e} 8$ and minimum stress is 32417 .

\begin{tabular}{|c|c|c|}
\hline STRESS & Steel(Max \& Min) & Nichrome(Max \& Min) \\
\hline Equivalent stress & $1.7187 \mathrm{e} 8 \& 31679$ & $1.7687 \mathrm{e} 8 \& 32417$ \\
\hline
\end{tabular}

Table.1. Maximum \& Minimum Stress for Steel \& Nichrome

\section{Strain:}

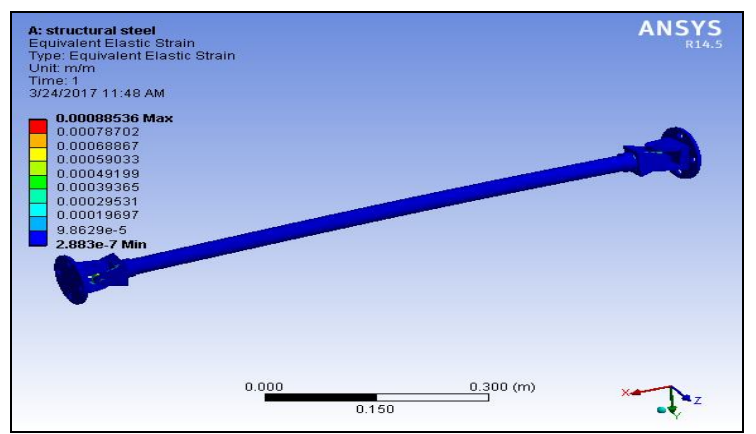

Fig.7. Strain of steel

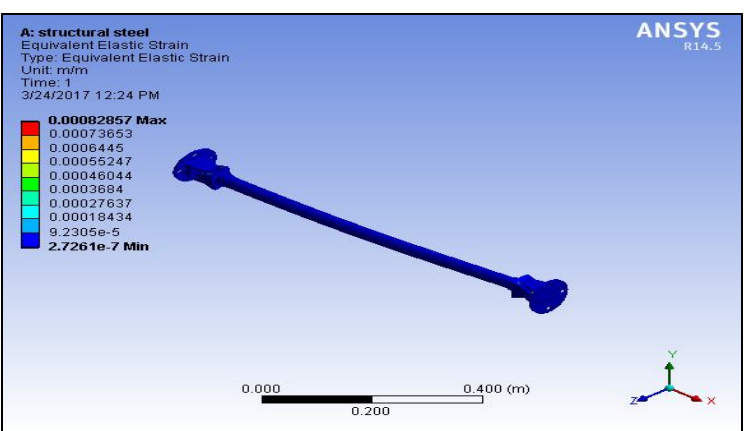

Fig.8. Strain of nichrome

\begin{tabular}{|c|c|c|}
\hline STRAIN & Steel(Max \& Min) & Nichrome(Max \& Min) \\
\hline Equivalent Elastic Strain & $0.00088536 \& 2.883 \mathrm{e}-7$ & $0.00082857 \& 2.7261 \mathrm{e}-7$ \\
\hline
\end{tabular}

Table.2. Maximum \& Minimum Strain For steel \& Nichrome

\section{Deformation:}
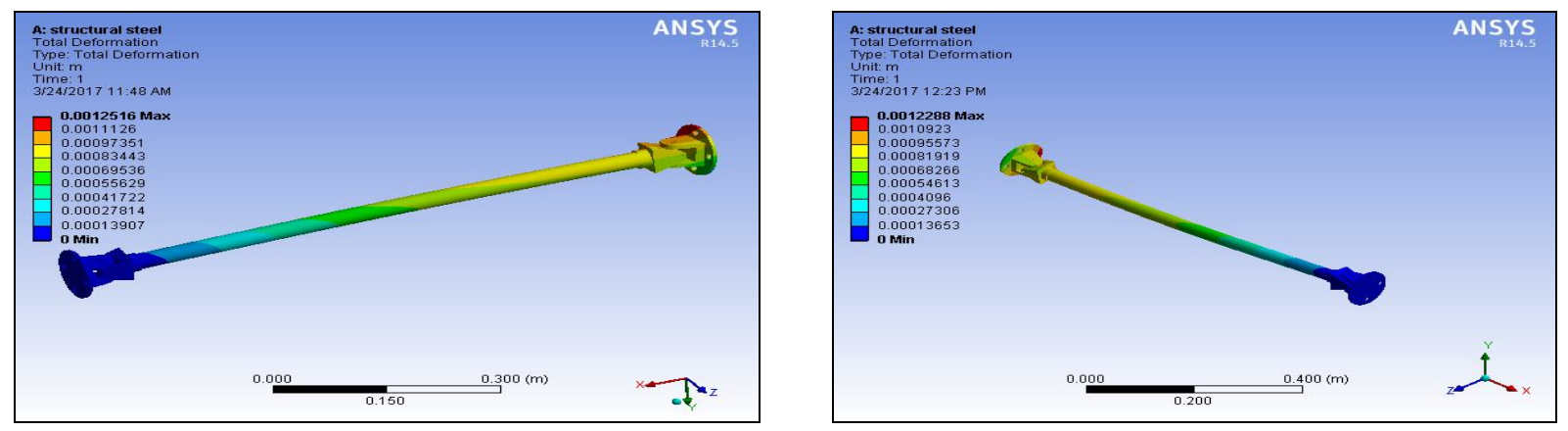
Fig.9. Total Deformation of steel

Fig.10. Total Deformation of nichrome

Fig.9.The maximum value for total deformation of steel is 0.0012516 .

Fig.10.The maximum value for total deformation of nichrome is 0.0012288 .

\begin{tabular}{|c|c|c|}
\hline Total Deformation & Steel(Max \& Min) & Nichrome(Max \& Min) \\
\hline Total deformation & $0.0012516 \& 0$ & $0.0012288 \& 0$ \\
\hline
\end{tabular}

Table.3. Total Deformation for Steel \& Nichrome

MODEL ANALYSIS OF PROPELLER SHAFT:

\section{Model: 1}

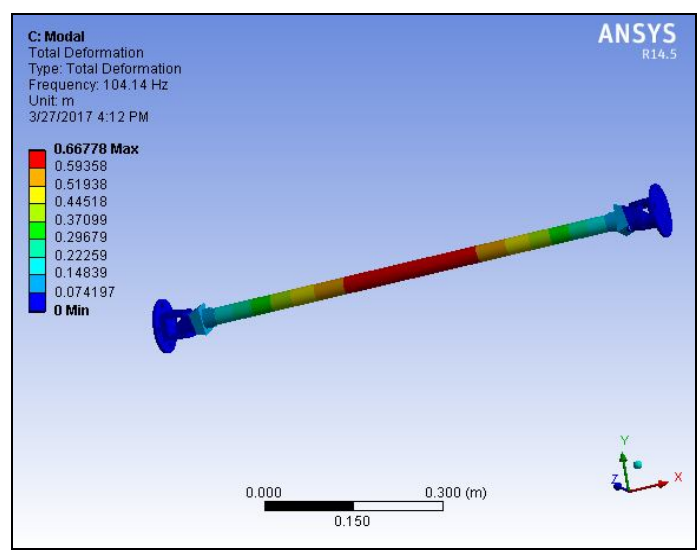

Fig.11 Total deformation of steel at 1

\section{Model: 2}



Fig.13 Total deformation of steel at 2

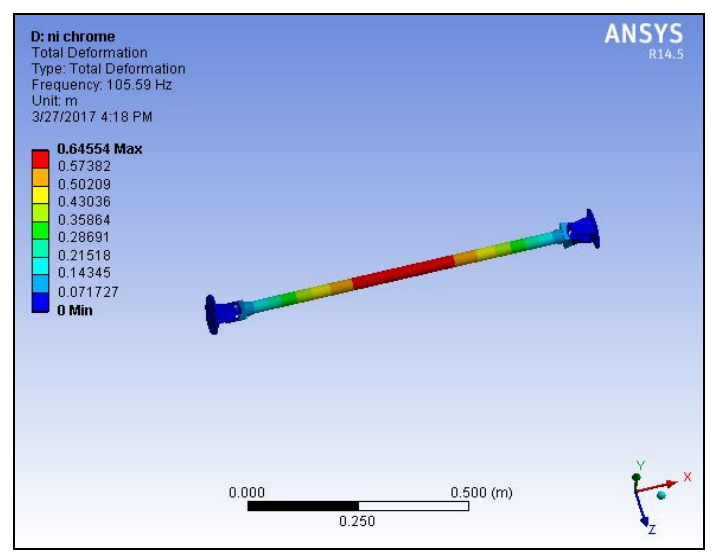

Fig.12 Total deformation of nichrome at 1

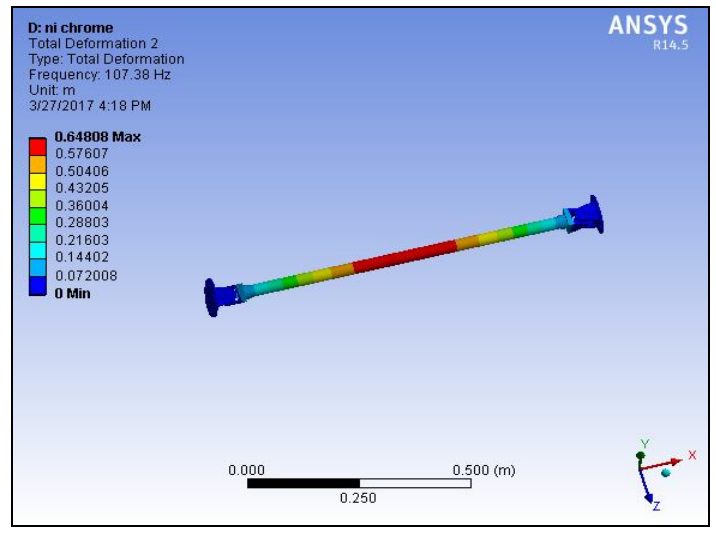

Fig.14 Total deformation of nichrome at 2

Model: 3 


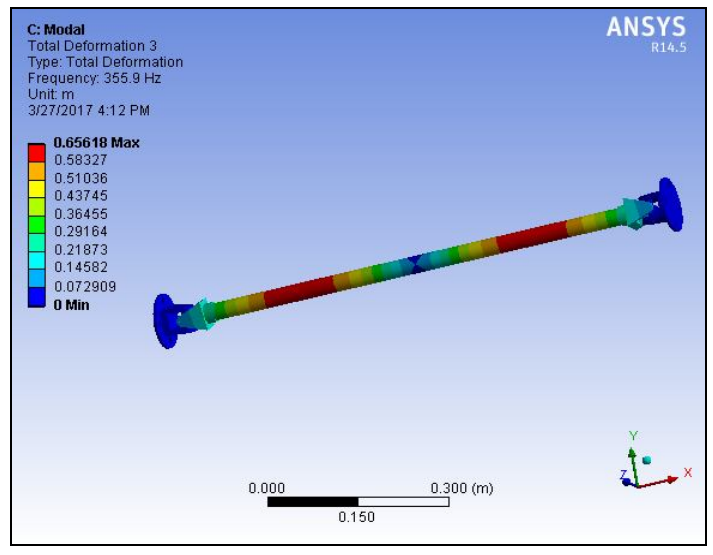

Fig.15 Total deformation of steel at 3

\section{Model: 4}

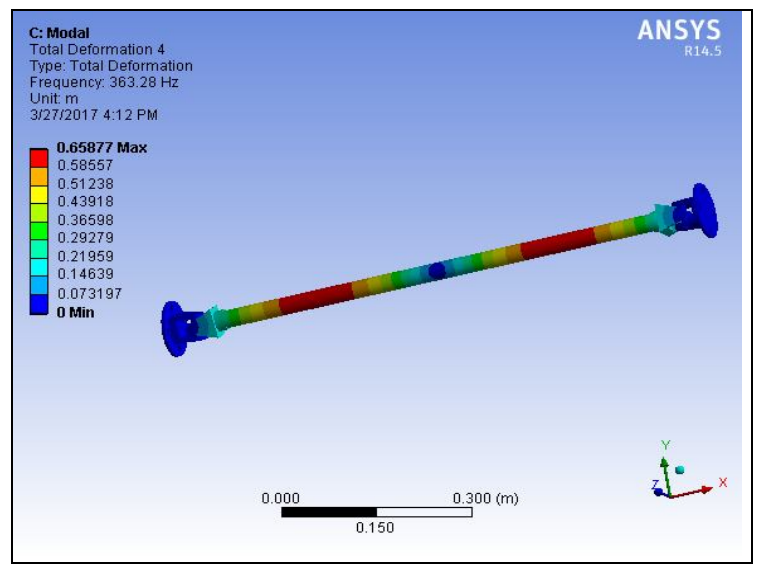

Fig.17.Total deformation of steel at 4

\section{Model: 5}

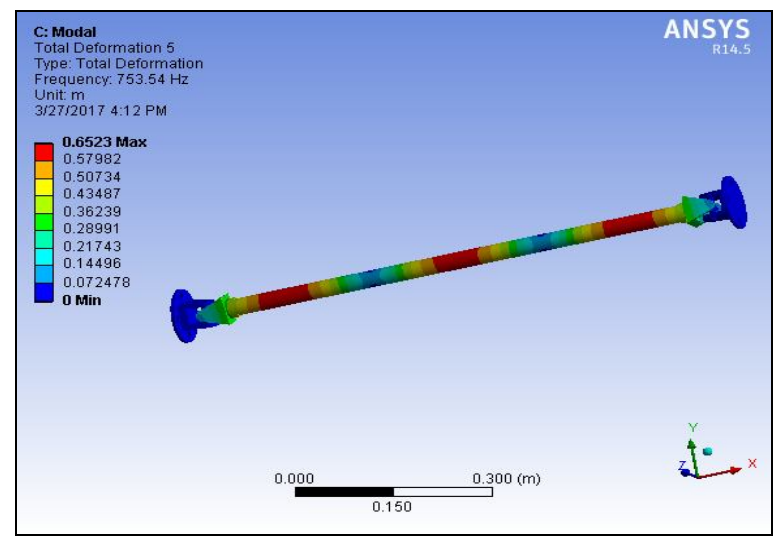

Fig.19 Total deformation of steel at 5

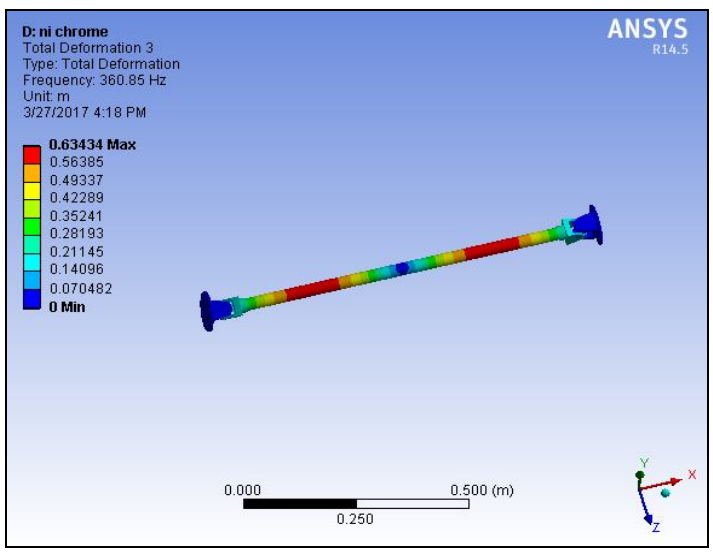

Fig.16Total deformation of nichrome at 3



Fig.18 Total deformation of nichrome at 4

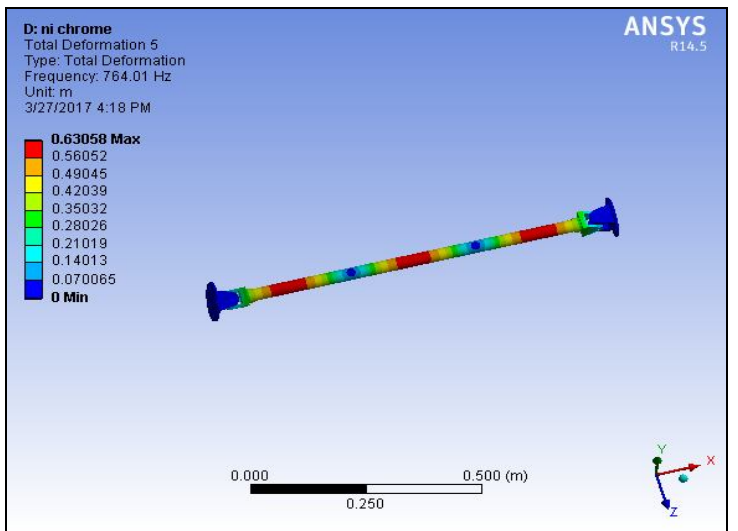

Fig.20 Total deformation of nichrome at 5

\section{Model: 6}




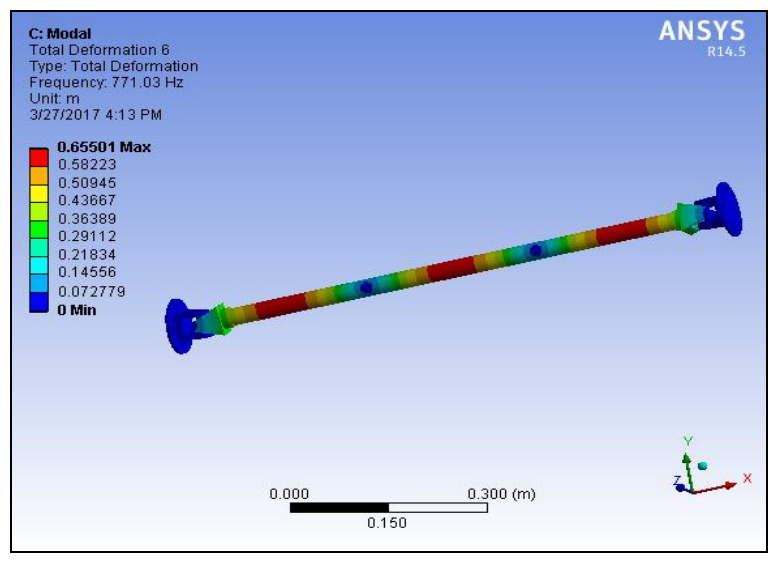

Fig.21 Total deformation of steel at 6

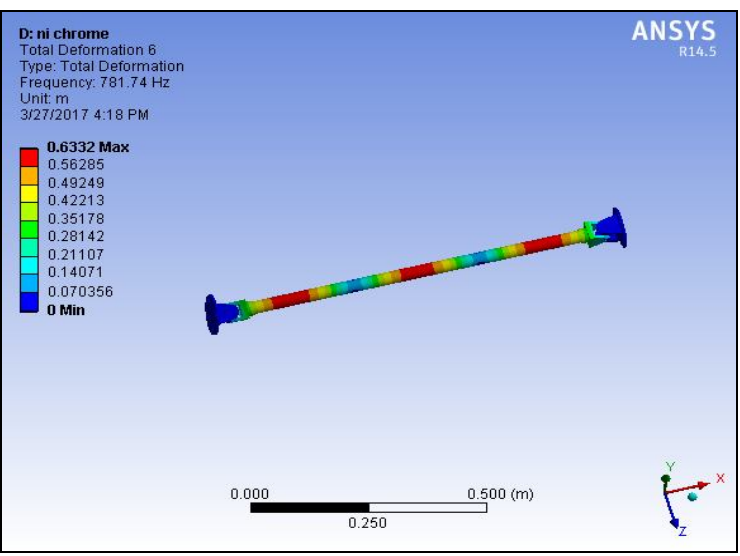

Fig.22 Total deformation of nichrome at 6

\begin{tabular}{|l|c|c|}
\hline \multicolumn{1}{|c|}{ MODEL ANALYSIS } & Steel(Max \& Min) & Nichrome(Max \& Min) \\
\hline Total deformation 1(mm) & $0.66778 \& 0$ & $0.64554 \& 0$ \\
\hline Total deformation 2(mm) & $0.6704 \& 0$ & $0.64808 \& 0$ \\
\hline Total deformation 3(mm) & $0.65618 \& 0$ & $0.63434 \& 0$ \\
\hline Total deformation 4(mm) & $0.65877 \& 0$ & $0.63684 \& 0$ \\
\hline Total deformation 5(mm) & $0.6523 \& 0$ & $0.63058 \& 0$ \\
\hline Total deformation 6(mm) & $0.65501 \& 0$ & $0.6332 \& 0$ \\
\hline
\end{tabular}

Table.4. Model Analysis

The maximum value of deformation of steel is $0.6704 \&$ for Ni-chrome is 0.64808 at model 2 and the minimum value is zero for all deformations.

\section{HARMONIC ANALYSIS:}

\section{Model 1:}

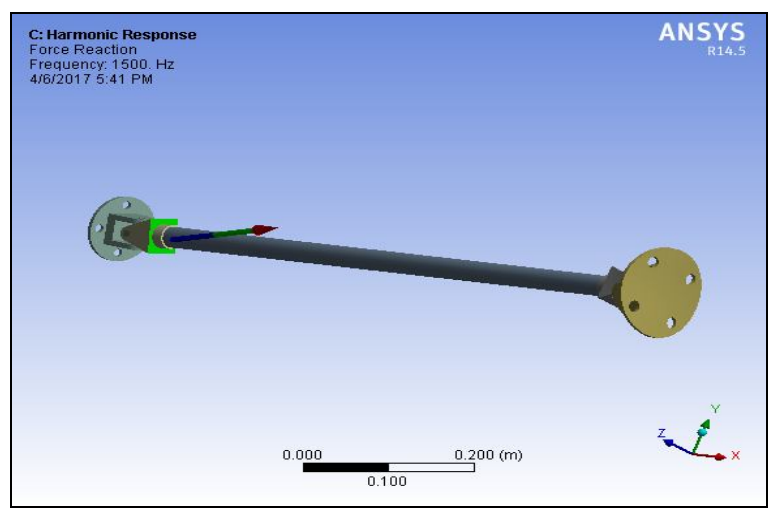

Fig.23 Harmonic analysis of steel 1

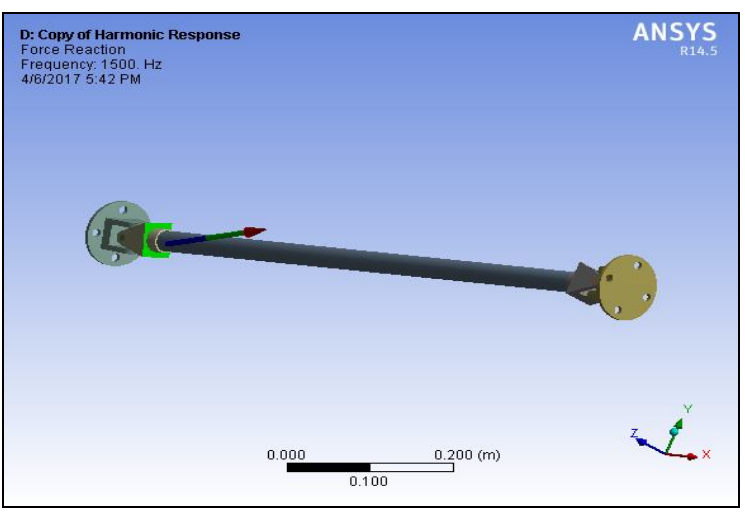

Fig.24 Harmonic analysis of Ni-chrome 1 
Model 2:

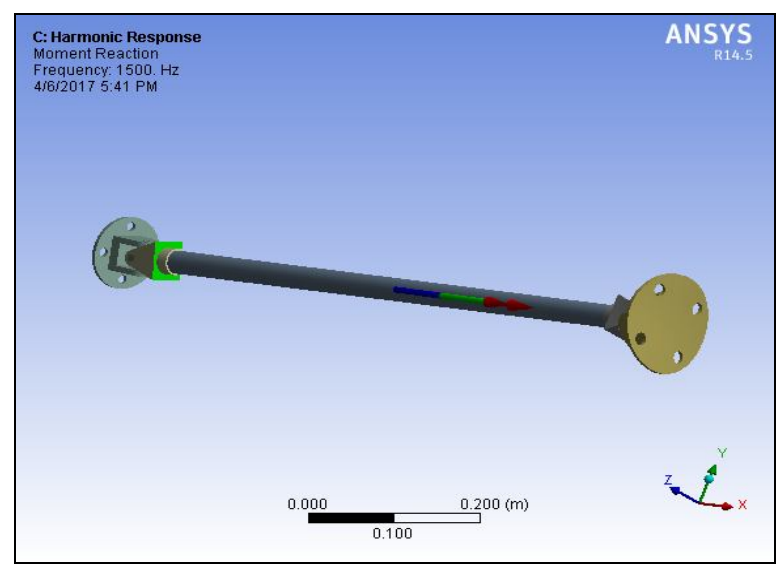

Fig.25 Harmonic analysis of steel 2

\section{GRAPHS:}

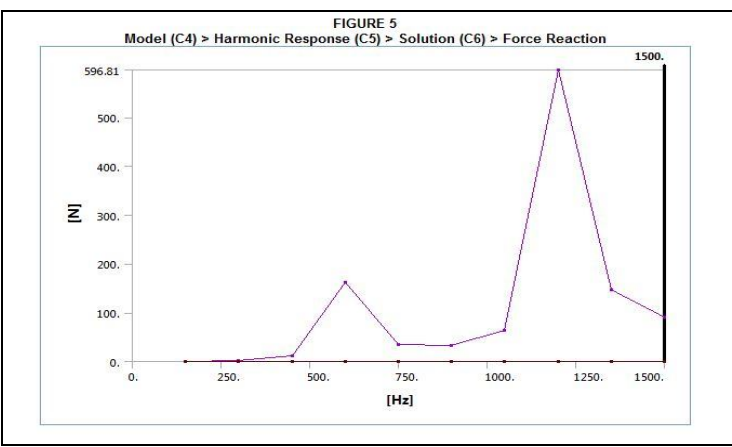

Graph.1. Harmonic analysis of steel model1

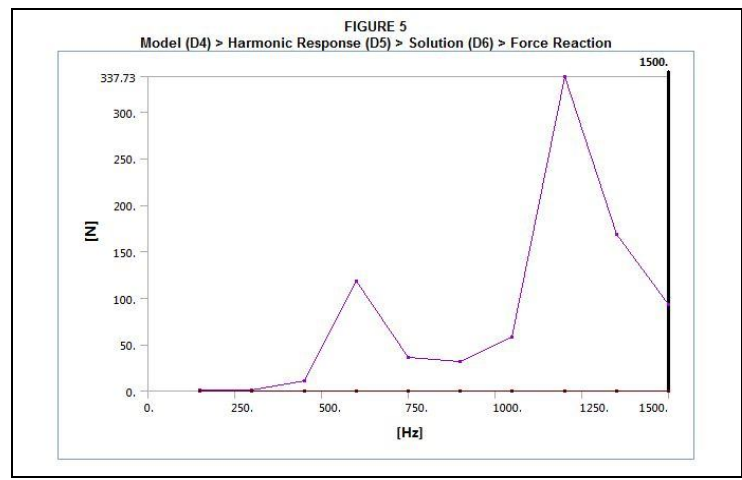

Graph.3. Harmonic analysis of Ni-chrome model1

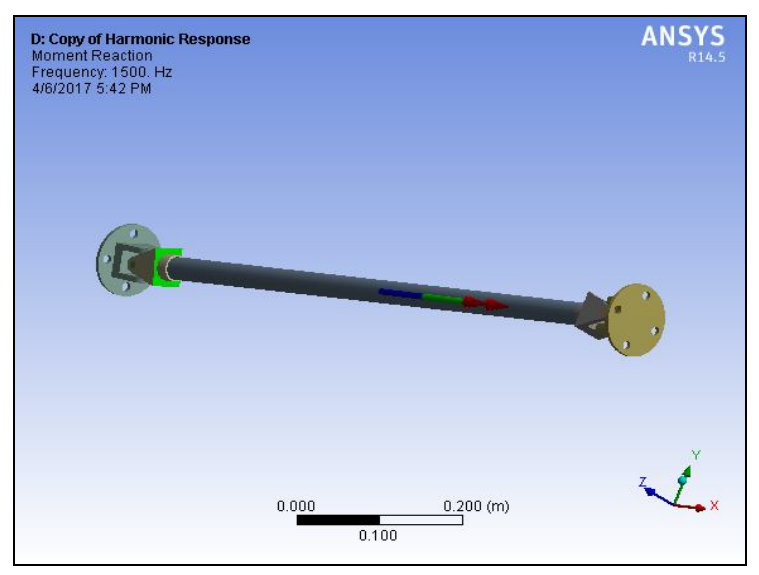

Fig.26 Harmonic analysis of Ni-chrome 2

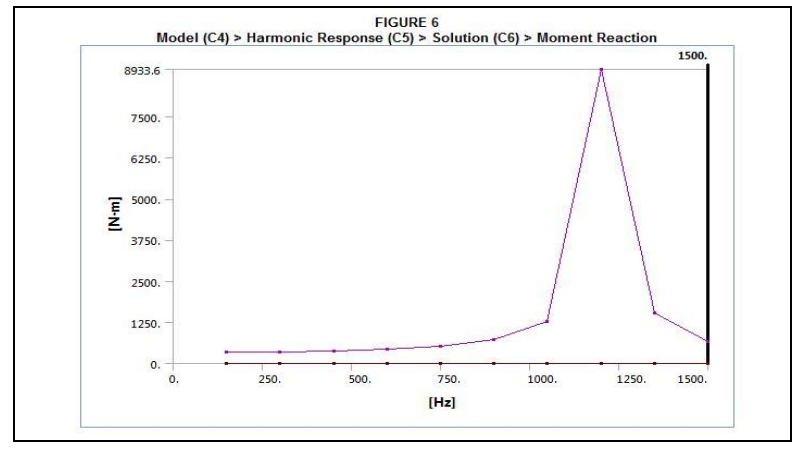

Graph.2. Harmonic analysis of steel model 2

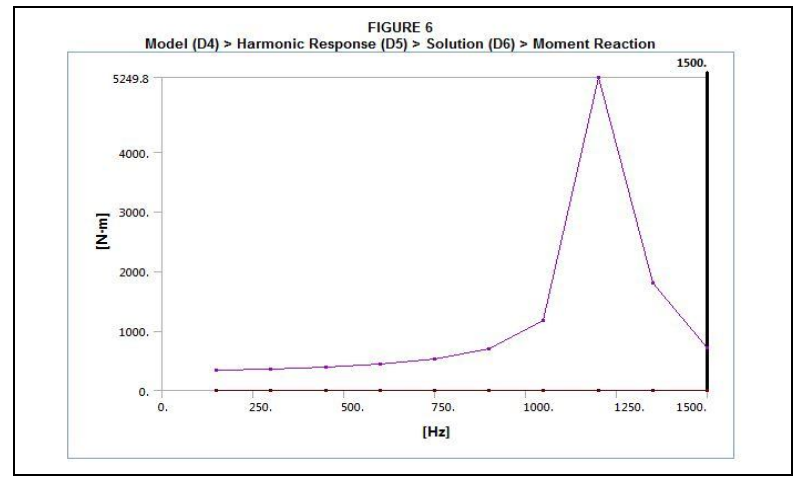

Graph.4. Harmonic analysis of Ni-chrome model 2

VI. RESULT

\begin{tabular}{|c|c|c|}
\hline Propeller shaft & Steel(Max \& Min) & Nichrome(Max \& Min) \\
\hline Elastic strain & $0.00088536 \& 2.883 \mathrm{e}-7$ & $0.00082857 \& 2.7261 \mathrm{e}-7$ \\
\hline
\end{tabular}




\begin{tabular}{|c|c|c|}
\hline Equivalent stress(N/mm2) & $1.7187 \mathrm{e} 8 \& 31679$ & $1.7687 \mathrm{e} 8 \& 32417$ \\
\hline Total deformation(mm) & $0.0012516 \& 0$ & $0.0012288 \& 0$ \\
\hline Model Analysis & & $0.64554 \& 0$ \\
\hline Total deformation $1(\mathrm{~mm})$ & $0.66778 \& 0$ & $0.64808 \& 0$ \\
\hline Total deformation $2(\mathrm{~mm})$ & $0.6704 \& 0$ & $0.63434 \& 0$ \\
\hline Total deformation 3(mm) & $0.65618 \& 0$ & $0.63684 \& 0$ \\
\hline Total deformation 4(mm) & $0.65877 \& 0$ & $0.63058 \& 0$ \\
\hline Total deformation 5 $(\mathrm{mm})$ & $0.6523 \& 0$ & $0.6332 \& 0$ \\
\hline Total deformation $6(\mathrm{~mm})$ & $0.65501 \& 0$ & \\
\hline
\end{tabular}

\section{CONCLUSION}

By theoretical comparison between steel and $\mathrm{Ni}-\mathrm{Cr}$ steel, $\mathrm{Ni}-\mathrm{Cr}$ steel is better in differential gear box manufacturing because of its high strength.

Though the cost of Ni-Cr is high, it has long life compared to Steel.

\section{ACKNOWLEDGEMENT}

The author is grateful to the management of AVN Institute of Engineering and Technology, Koheda, R.R.Dist., Telangana, India, for providing the facilities for the execution of this experimental analysis in the Computer Aided Design Laboratory of the Department of Mechanical Engineering and also to the students L.Nikhlesh, P.Akhilesh Goud, T.Sravan Kumar Reddy and J.V.Sai Teja for their support.

\section{REFERENCES}

[1] Muni kishore, Jaligam Keerthi, Vinay kumar \& quot;Design and Analysis of Drive Shaft of an Automobile \& quot ;, International Journal of Engineering Trends and Technology (IJETT), V38 (6),291-296 August 2016. ISSN: $2231-5381$.

[2] Virendra V. Maheta, Anup B. Patel. "Design, Analysis and Optimization in Automobile Drive Shaft". IJIRST International Journal for Innovative Research in Science \&amp; Technology| Volume 1 | Issue 12 | May 2015 ISSN (online): 2349-6010.

[3] Deepti kushwaha , Gaurav Sa., "Optimal Design And Analysis Of Composite Drive Shaft For A Light Commercial Vehicle" IJAERD-2014, All rights Reserved 107 ISSN (Print) : 2348- 6406ISSN (Online): 2348- 4470.

[4] IOSR Journal of Mechanical and Civil Engineering (IOSR-JMCE) e-ISSN: 2278-1684, p- ISSN: 2320-334X, Volume 10, Issue 2 (Nov. -Dec. 2013), PP 43-46. Analysis of a Drive Shaft for Automobile Applications P. Jayanaidu, M. Hibbatullah, Prof. P. Baskar.

[5] Sagar. R. Dharmadhikari, Sachin. G. Mahakalkar, Jayant P Giri, Nilesh D Khutafale "Design and Analysis of Composite Drive Shaft using ANSYS and Genetic Algorithm” IJMER Jan-Feb. 2013, pp-490- 496. 
[6] H. Bayrakceken *, S. Tasgetiren, _I. Yavuz; Two cases of failure in the power transmission system on vehicles: A universal joint yoke and a drive shaft, Engineering Failure Analysis, 14 (2007) 716-724.

[7] S.A. Mutasher; Prediction of the torsional strength of the hybrid aluminium /composite drive shaft, Materials and Design 30 (2009) 215- 220

[8] 1Anup A. Bijagare*, 2P.G. Mehar and 3V.N. Mujbaile; Design Optimization \&amp; Analysis of Drive Shaft, VSRD-MAP, Vol. 2 (6), 2012, 210-215.

[9]Arun Ravi: Design, comparison and analysis of a composite drive shaft for an automobile,International Review of Applied Engineering Research. ISSN 2248-9967 Volume 4, Number 1 (2014), pp. 21-28

[10] Felipe Moura Fontes Novo, Mauro Moraes de Souza, Juliano Savoy, Marcelo Adriano do Carmo Silva, "Analysis of the vibration modes of an automotive propeller shaft using FEM and analytical models"SAE-2012- 360224 .

[11] A.M.Ummuhaani, Dr.P.Sadagopan, "Design, Fabrication and Stress Analysis of a Composite Propeller Shaft" SAE-2011- 28-0013. 